\title{
Analisis Nilai Moral Buku Baban Kana dan Pengembangannya Sebagai Bahan Ajar Cerpen Berbasis Kearifan Lokal
}

\section{Perempuan Fitri Ayu ${ }^{\text {* }}$ \\ Indrya Mulyaningsih ${ }^{1}$ \\ Emah Khuzaemah ${ }^{1}$ \\ ${ }^{* 1}$ 1IAIN Syekh Nurjati Cirebon, Indramayu, Jawa Barat, Indonesia \\ *email: puanfitriayu28@gmail.com}

Received: 23 Februari 2021

Accepted: 27 Maret 2021

Published: 27 Maret 2021

doi: $10.22236 /$ imajeri.v3i2.6580

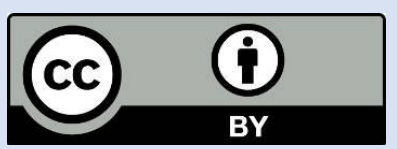

(C) 2021 Oleh authors. Lisensi Imajeri: Jurnal Pendidikan Bahasa dan Sastra Indonesia, Uhamka, Jakarta. Artikel ini bersifat open access yang didistribusikan di bawah syarat dan ketentuan Creative Commons Attribution (CC-BY) license.

(http://creativecommons.org/licenses/by/4.0/).

\begin{abstract}
Abstrak
Pesatnya arus globalisasi memengaruhi kehidupan pelajar zaman sekarang, kenakalan yang terjadi menandakan bahwa moral pelajar Indonesia sedang krisis, begitupun dengan kehidupan pelajar yang lebih menyukai budaya asing dibandingkan budaya di daerahnya sendiri. Tujuan dari penelitian ini adalah untuk menganalisis nilai-nilai moral yang terkandung dalam buku sejarah Cirebon yang belum banyak dikaji yaitu Baban Kana. Melihat berbagai kasus krisis moral yang terjadi pada pelajar, maka perlu adanya pengembangan bahan ajar berupa buku teks yang di dalamnya memuat nilai-nilai moral yang dapat dipelajari dan diterapkan dalam kehidupan sehari-hari. Metode dalam penelitian ini yaitu analisis isi atau content analysis, Teknik pengumpulan data menggunakan teknik Pustaka, Baca dan Catat. Berdasarkan hasil penelitian dan pembahasan terhadap buku Baban Kana karya KH. Zamzami Amin dapat ditarik kesimpulan bahwa nilai moral hubungan manusia dengan Tuhannya ditemukan 11 kutipan, nilai moral hubungan manusia dengan diri sendiri ditemukan 44 kutipan, nilai moral hubungan manusia dengan orang lain ditemukan 7 kutipan. Penelitian ini juga mengembangkan bahan ajar berupa buku teks yang berjudul Pembelajaran Cerpen Berkearifan Lokal untuk kelas XI SMA. Kata kunci: Nilai Moral; Bahan Ajar; Kearifan Lokal
\end{abstract}

\section{Abstract}

The rapid development of globalization affects to students' thinking and manner. Student misbehavior that occurred indicates that the morale of Indonesian students is in crisis, as well as they prefer a foreign culture than the local culture. The purpose of this study is to analyze the moral values contained in Cirebon history books that have not been much studied, namely Baban Kana. Seeing various cases of moral crisis that occur in our students, it is necessary to develop teaching materials in the form of textbooks that contain moral values that can be learned to be applied in everyday life. The method of this research is content analysis, Data collection techniques using library research, reading and note taking. Based on the results of this research and discussion of the book Baban Kana by KH. Zamzami Amin concluded that the moral value of human relations with Go, the moral value of human relations with oneself, the moral value of human relations with others. This study also developed teaching materials in the form of a textbook entitled Indonesian Language Learning for Short Story Local Wisdom for class XI of high school.

Keywords: Moral values; Teaching materials; Local wisdom 


\section{PENDAHULUAN}

Bangsa Indonesia sedang dilanda duka, karena keadaan moral generasi muda khususnya pelajar pada saat ini. Televisi, koran, media sosial setiap hari selalu ada yang diberitakan tentang rusaknya moral remaja dan pelajar Indonesia. Berdasarkan data dari Komisi Perlindungan Anak Indonesia (KPAI), jumlah kasus kekerasan terhadap anak Indonesia dibidang pendidikan per oktober 2019 sebanyak 161 kasus. Perinciannya kasus pada korban tawuran 23 kasus, kasus pelaku tawuran 31 kasus, dan korban anak dari kekerasan dan perundungan 36 kasus. Kemorosotan moral merupakan permasalahan yang harus memiliki solusi yang baik, salah satu caranya dengan menyisipkan nilai-nilai moral pada pembelajaran di sekolah, contohnya dalam pembelajaran sastra. Dalam Sejarah banyak terkandung nilainilai, khususnya nilai moral yang patut dipelajari oleh siswa untuk menjadi pribadi yang memiliki etika dan berbudi luhur sesuai dengan norma dan hukum yang berlaku.

Moral merupakan makna yang terkandung dalam sebuah karya sastra, pembaca dapat mengambil pesan moral dari karya sastra yang sudah dibacanya melalui tingkah laku sikap cerita tokoh dalam sebuah karya sastra yang telah dibacanya (Safitri, 2020). Dengan demikian untuk menanamkan pemahaman sejarah dan meningkatkan kualitas moral pada pelajar karya sastra khususnya sastra kearifan lokal dapat dijadikan sumber dalam memahami dan meneladani nilai-nilai moral. Pesatnya perkembangan globalisasi berdampak negatif bagi para pelajar, karena banyak pelajar yang tidak mengetahui dan memahami sejarah bangsanya sendiri, bahkan dalam cakupan yang lebih sempit yaitu sejarah tentang daerah atau tempat tinggalnya.

Sastra merupakan hasil dari pengolahan bahasa dan budaya yang diciptakan oleh manusia. Menurut Wiyatmi (2006) sastra adalah sebuah tulisan yang memiliki keunikan, keindahan dan unggul jika dibandingkan dengan tulisan lain. Sastra juga merupakan sarana untuk menyampaikan nilai-nilai karakter (Dewi, Hidayatullah, \& Puspitasari, 2020; Youpika $\&$ Zuchdi, 2016). Tujuan dari penelitian ini untuk menganalisis nilai-nilai moral pada buku Baban Kana yang merupakan salah satu sejarah lokal yang belum banyak dikaji secara komprehensif. (Purwaningsih, 2010)Nilai merupakan sesuatu yang dapat berguna, berharga bagi individu untuk dijadikan sebuah pedoman diri sekaligus dapat dijadikan sebuah acuan normatif tentang suatu keyakinan individu baik secara psikologis maupun sosiologis (Solihati, Hikmat, Jupri, \& Hidayatullah, 2019). Menurut Kenny (dalam Nurgiyantoro, 2015) moral dalam karya sastra adalah cerita yang dikehendaki sebagai suatu saran yang bisa berhubungan dengan ajaran moral tertentu yang bersifat praktis, dan dapat diambil atau bisa ditafsirkan lewat sebuah cerita yang bersangkutan dengan para pembaca.

Guna mencapai tujuan menganalisis nilai-nilai moral pada buku Baban Kana menggunakan metode analisis isi atau content analysis, menurut Vredenbreght (dalam Ratna, 2013) menyatakan bahwa metode analisis isi atau analisis isi merupakan sebuah metode yang digunakan untuk memahami teks dan mengungkap karya sastra yang kemudian ditafsirkan dengan deskripsi, dalam karya sastra yang dimaksud itu isi dari pesan- pesan, yang sesuai 
dengan hakikat sastra. Kemeoroston moral yang terjadi pada pelajar Indonesia harus segera diatasi, karena pelajar merupakan harapan bangsa dimasa yang akan datang.

Melihat kebutuhan pelajar maka dalam penelitian ini kemudian mengembangkan bahan ajar buku teks cerpen melalui pembelajaran apresiasi sastra yang dinilai sangat efektif diterapkan dalam membina karakter peserta didik. Membuka kesadaran pelajar melalui cerita merupakan cara yang cukup efektif, saat membaca cerita perasaan siswa mudah terbawa oleh alur cerita. Dalam Kurikulum 2013 cerpen merupakan materi ajar sastra, materi ini untuk jenjang SMA kelas XI semester ganjil. Pengembangan bahan ajar buku teks yang dilakukan berkaitan dengan Kompetensi Dasar (KD) yang terdapat dalam kurikulum 2013, yaitu Kompetensi Dasar (KD) 3.8 Mengidentifikasi nilai-nilai kehidupan yang terkandung dalam kumpulan cerita pendek yang dibaca dan Kompetensi Dasar 4.8 Mendemonstrasikan salah satu nilai kehidupan yang dipelajari dalam cerita pendek.

\section{METODE}

Penelitian ini tergolong ke jenis penelitian kualitatif, penelitian kualitatif akan menghasilkan sebuah data deskriptif yang berupa kata-kata tertulis atau lisan tentang suatu keadaan, individu, gejala dari kelompok tertentu yang dapat diamati (Moleong, 2013). Penelitian ini merupakan penelitian studi kepustakaan, waktu penelitian dilakukan pada bulan Maret sampai Juli 2020. Sesuai dengan kurikulum, silabus, KI dan KD yang sudah ditentukan, maka subjek pada pengembangan bahan ajar buku teks berbasis kearifan lokal yaitu siswa kelas XI SMA sederajat. Teknik dan instrumen pengumpulan data yang dilakukan menggunakan Tenik Pustaka baca dan catat dan instrumen Kartu Data untuk mencatat wujud nilai moral. Tahap analisis menggunakan metode analisis isi untuk menafsirkan nilai moral yang terkandung dalam buku Baban Kana. Penelitian kualitatif disebut dengan pemeriksaan keabsahan data pada bagian pengujian validitas dan reliabilitas, untuk menguji keabsahan data perlu digunakan triangulasi. Triangulasi yang digunakan dalam penelitian ini yaitu triangulasi teori, sumber data dan metode.

Penilaian kelayakan bahan ajar buku teks menggunakan formulir penilaian, menurut menurut Badan Standar Nasional Pendidikan (BSNP) komponen dalam penilaian kelayakan bahan ajar buku teks pelajaran meliputi empat komponen yaitu; 1) kelayakan isi, 2) kekayaan bahasa, 3) kelayakan penyajian, dan 4) kelayakan kegrafikan. Rentang nilai yang diberikan pada tiap poin adalah satu sampai lima, dengan nilai terendah satu dan tertinggi adalah lima. Uji Validasi dilakukan oleh pakar ahli Bahasa Indonesia yaitu dosen pembimbing satu dan dua peneliti. Buku teks yang berjudul Pembelajaran Cerpen Berbasis Kearifan Lokal layak digunakan karena sudah tervalidasi. Adapun langkah-langkah yang dilakukan dalam penilaian kelayakan buku teks adalah sebagai berikut; 1) penguji mengisi nilai pada formulir penilaian kelayakan buku teks, 2) menghitung nilai menggunakan rumus sebagai berikut. 


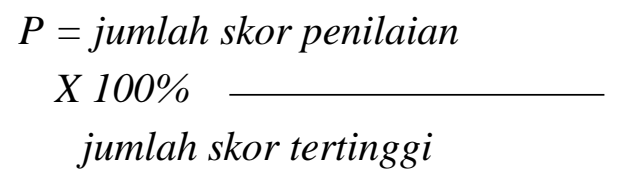

Hasil dari penilaian untuk mengetahui kelayakan buku teks yang dikembangkan dengan menggunakan tabel perhitungan kelayakan sebagai berikut.

Tabel 1. Perhitungan Kelayakan

\begin{tabular}{|l|l|}
\hline Presentase & Kategori \\
\hline $0 \%-20 \%$ & Tidak baik \\
\hline $21 \%-40 \%$ & Kurang baik \\
\hline $41 \%-60 \%$ & Cukup baik \\
\hline $61 \%-80 \%$ & Baik \\
\hline $81 \%-100 \%$ & Sangat baik \\
\hline
\end{tabular}

Nilai kelayakan buku teks sebagai bahan ajar ditentukan dengan nilai minimal $61 \%$ dengan kategori baik.

\section{HASIL DAN PEMBAHASAN}

\section{Wujud Nilai-nilai Moral yang Terkandung dalam Buku Baban Kana Karya KH. Zamzami Amin}

Baban Kana adalah sebuah buku yang diangkat dari kisah nyata sejarah Pondok Pesantren Babakan Ciwaringin Cirebon dan Perang Nasional Kedongdong 1802-1919, di Babakan Ciwaringin pernah terjadi perang yang luar biasa antara masyarakat melawan penjajah Belanda, perang tersebut berlangsung sangat lama yakni semenjak tahun 1802-1919 dan perang tersebut dikenal dengan nama "Perang Kedongdong". Dalam buku Baban Kana tidak hanya menceritakan perang Kedongdong saja, namun juga menceritakan perjuangan Sunan Gunung Jati dan ulama-ulama Cirebon dalam menyebarkan agama islam di Jawa Barat, proses dakwah yang dilakukan diwarnai juga dengan perang-perang yang skalanya kecil. Nilai moral dalam buku Baban Kana bisa dijadikan contoh dalam kehidupan sehari-hari, nilai moral dalam buku ini misalnya semangat juang para ulama dan santri dalam memperjuangkan kemerdekaan Indonesia yang begitu luar biasa. Nilai-nilai moral dalam karya sastra bisa ditemukan dalam tiga aspek kehidupan, ketiga aspek kehidupan tersebut dapat meliputi hubungan manusia dengan Tuhan, hubungan manusia dengan dirinya sendiri, hubungan manusia dengan orang lain Nurgiyantoro (Mangunwijaya, 1994).

Menurut Nurgiyantoro (dalam Muplihun, 2016) hubungan manusia dengan Tuhan yaitu hubungan yang paling sakral. Manusia adalah mahluk yang tidak pernah lepas dari penciptaNya. Nilai moral hubungan manusia dengan Tuhan diantaranya mengenal Tuhan dan akhlak 
terhadap Tuhan (Hidayatullah, 2020). Menurut Zuriah (2015) perilaku hubungan manusia dengan dirinya sendiri dapat dibagi dalam semua wujud yang berhubungan dengan setiap individu dengan berbagai karakter, diantaranya nilai religius, sosial, demokrasi, daya juang, tanggung jawab, penghargaan terhadap lingkungan alam, disiplin, mandiri, rasa hormat, sabar, kebaikan hati, kerja keras, dan jujur.

Hubungan manusia dengan orang lain dapat diwujudkan dengan menghormati orang lain, baik tetangga atau masyarakat sekitar dengan latar belakang budaya, adat, agama dan kasta yang berbeda (Zubaedi, 2012). Menurut Nurgiyantoro (dalam Muplihun, 2016) hubungan manusia dengan orang lain dibagi menjadi tiga, diantaranya kekeluargaan, kesetiaan dan persahabatan. Wujud nilai moral yang terdapat dalam buku Baban Kana tersaji dalam tabel berikut.

Tabel 1. Wujud Nilai Moral dalam Buku Baban Kana

\begin{tabular}{|l|l|c|}
\hline No. & Indikator & Jumlah \\
\hline 1. & Hubungan manusia dengan Tuhan & 11 \\
\hline 2. & Hubungan manusia dengan diri sendiri & 44 \\
\hline 3. & Hubungan manusia dengan orang lain & 7 \\
\hline Total & 62 \\
\hline
\end{tabular}

Contoh nilai moral hubungan manusia dengan Tuhan terdapat dalam kutipan sebagai berikut.

Keyakinan merupakan pokok utama seseorang dalam memegang teguh ajaran agamanya, tanpa meyakini ajaran agamanya, tentu seseorang mengalami kegamagan dalam menentukan sikap sebagai seorang yang beragama.

Masyarakat Cirebon pada saat itu ingin meminta permohonan kepada Tuhan agar mata pencahariannya dapat berhasil, khususnya para petani yang meminta agar hasil panennya baik dan dapat hidup aman dan tentram, oleh karena itu masyarakat Cirebon menyelenggarakan do'a bersama untuk mengungkapkan rasa syukur kepada Tuhan yang Maha Esa atas rahmat yang telah dilimpahkannya. Masyarakat Cirebon meyakini ajaran agama, dan percaya bahwa do'a yang dipanjatkan akan dikabulkan oleh Tuhan merupakan pokok utama seseorang dalam beragama. Sikap mengenal Tuhan dapat ditunjukkan dengan yakin dan percaya terhadap Tuhannya, ketika manusia mengenal Tuhan maka manusia tersebut akan semakin yakin terhadap kekuasaan pecipta-Nya.

Contoh nilai moral hubungan manusia dengan diri sendiri terdapat dalam kutipan sebagai berikut.

Pada tahun 1721, Ki Jatira datang lagi ke Pedukuhan Babakan untuk meneruskan syiar islamnya yang kemudian membangun kembali padepokan yang telah hancur. (hal 142)

Pada tahun 1718 serdadu Belanda datang dan menyerang Padepokan Ki Jatira di Babakan, karena persitiwa perang tersebut Padepokan Ki Jatira dihancurkan dan dibakar habis 
oleh penjajah. Perang tersebut dinamakan Perang Jatira, para santri beliau juga turut menjadi korban penyerangan tersebut, ketika itu Ki Jatira tidak bisa meneruskan syiar islamnya karena Padepokannya telah hancur. Namun Ki Jatira tetap bisa menyelesaikan persoalan hidupnya, ia menunjukkan perilaku mandiri dengan datang seorang diri ke pedukuhan Babakan dan membangun kembali padepokan tersebut pada tahun 1721. Setelah padepokan tersebut dibangun, Ki Jatira mulai melanjutkan syiar islamnya kepada masyarakat sekitar dan beberapa santri dari berbagai daerah yang sengaja datang ke padepokan Ki Jatira.

Contoh nilai moral hubungan manusia dengan orang lain terdapat dalam kutipan sebagai berikut.

Dua tahun kemudian, KH. Sanusi salah satu murid KH. Amin Sepuh orang yang pertama kali datang dari pengungsiannya, kemudian sisa-sisa kitab suci yang berantakan, bangunan hancur secara bertahap dibereskan lagi.

Pada tahun 1952 Pondok Pesantren Babakan Cirebon diserang Belanda, penyerangan tersebut dikarenakan pengasuh Pondok Pesantren KH. Amin Sepuh merupakan pejuang yang menentang penjajah. Pondok Pesantren berhasil dikepung dan dibakar, hingga bangunannya hancur tak tersisa. Ketika Pondok dikepung penjajah, para santri, pengasuh dan keluarga pergi mengungsi, namun beberapa tahun kemudian salah satu santri KH. Amin Sepuh yaitu KH. Sanusi datang ke Pondok Pesantren untuk membereskan sisa-sisa kitab suci yang berantakan, kedatangan KH. Sanusi menunjukkan kesetiaan dan tad'zim seorang murid terhadap gurunya.

\section{Pengembangan Bahan Ajar Buku Teks Cerpen Berbasis Kearifan Lokal Cirebon Sesuai Kebutuhan Pelajar}

Pesatnya arus globalisasi memengaruhi pemikiran dan kehidupan pelajar zaman sekarang, banyak ditemukan kenakalan remaja seperti tawuran antar sekolah, melawan guru, perundungan dan lain-lain. Kenakalan pelajar yang terjadi menandakan bahwa moral pelajar Indonesia sedang krisis, begitupun dengan kehidupan pelajar yang lebih menyukai budaya asing dibandingkan budaya di daerahnya sendiri. Menurut Komisi Perlindungan Anak Indonesia (KPAI) mengatakan bahwa krisis moral yang terjadi pada pelajar harus segera di atasi dan diprioritaskan, karena pelajar merupakan harapan bangsa di masa yang akan datang.

Pelajar membutuhkan suatu pembelajaran yang di dalamnya dapat membina karakter dan membuka kesadaran siswa, dengan hal ini pembelajaran sastra sangat efektif diterapkan dalam membina karakter peserta didik. Membuka kesadaran siswa melalui cerita merupakan cara yang efektif, karena saat membaca cerita perasaan siswa mudah terbawa oleh alur cerita yang dibaca. Pada saat bersamaan, sebenarnya karya sastra sedang membentuk karakter (Puspitasari, Hidayatullah, \& Jupri, 2018). Dalam kurikulum 2013 cerpen merupakan materi ajar sastra, materi ini untuk jenjang SMA kelas XI semester ganjil. Sesuai kebutuhan siswa sekarang, maka perlu adanya pengembangan bahan ajar berupa buku teks yang di dalamnya memuat nilai-nilai moral yang dapat dipelajari siswa untuk diterapkan dalam kehidupan sehari-hari, dan juga buku yang membahas tentang kearifan lokal daerah agar siswa dapat lebih mencintai budaya daerahnya sendiri dibandingkan budaya asing. 
Dalam penelitian ini yaitu mengembangkan bahan ajar berupa buku teks mengenai materi cerita pendek (cerpen), buku teks yang dikembangkan sesuai dengan kurikulum dan kebutuhan siswa. Pada pembuatan bahan ajar buku teks cerpen disesuaikan dengan Kompetensi Dasar (KD) yang terdapat dalam kurikulum 2013, yaitu Kompetensi Dasar (KD) 3.8 Mengidentifikasi nilai-nilai kehidupan yang terkandung dalam kumpulan cerita pendek yang dibaca dan 4.8 Mendemonstrasikan salah satu nilai kehidupan yang dipelajari dalam cerita pendek.

Produk bahan ajar ini berupa buku teks berbasis kearifan lokal yang diberi judul Bahasa Indonesia Pembelajaran Cerpen Berkearifan Lokal, buku teks yang dikembangkan dalam penelitian ini untuk kelas XI SMA/SMK/MA. Adapun bagian yang ada dalam buku teks meliputi halaman identitas, kata pengantar, daftar isi, pembelajaran sastra, peta konsep, materi, rangkuman, uji kompetensi dan daftar pustaka.

Setelah pengembangan buku teks Bahasa Indonesia Pembelajaran Cerpen Berkearifan Lokal untuk memperoleh data bahwa buku teks tersebut layak atau tidak digunakan sebagai bahan ajar maka akan dilakukan penilaian kelayakan buku oleh dosen ahli bahasa Indonesia yang merupakan dosen pembimbing satu dan dua peneliti. Hasil penilaian kelayakan yang dilakukan, maka produk yang dihasilkan dalam penelitian ini layak digunakan karena sudah memenuhi standar, buku teks yang berjudul Bahasa Indonesia Pembelajaran Cerpen Berkearifan Lokal bisa digunakan untuk pembelajaran cerpen kelas XI SMA sederajat.

\section{KESIMPULAN}

Penelitian ini menganalisis nilai moral dalam buku Baban Kana karya KH. Zamzami Amin, wujud nilai moral dalam buku Baban Kana terdiri dari tiga bentuk, ketiga bentuk tersebut yaitu hubungan manusia dengan Tuhan, hubungan manusia dengan diri sendiri, dan hubungan manusia dengan orang lain. Jumlah nilai moral yang ditemukan dan dianalisis dalam buku Baban Kana yaitu 62 nilai moral, setelah melakukan analisis, peneliti mengembangkan bahan ajar berupa buku teks yang berjudul Pembelajaran Cerpen Berbasis Kearifan Lokal yang dibuat sesuai dengan kurikulum dan kebutuhan siswa.

Pada pengembangan buku teks di dalamnya memuat nilai-nilai moral yang dapat diterapkan dalam kehidupan sehari-hari, dalam buku teks tersebut juga membahas kearifan lokal agar siswa dapat mengenal budaya lokal di daerahnya sendiri. Buku teks yang dikembangkan sesuai dengan BSNP yang dinilai kelayakannya oleh dosen ahli Bahasa Indonesia yang merupakan dosen pembimbing satu dan dua peneliti. Dari hasil penilaian kelayakan menunjukkan bahwa buku teks yang sudah dikembangkan dalam penelitian ini memenuhi kriteria dan layak untuk digunakan sebagai bahan ajar untuk kelas XI SMA.

\section{DAFTAR PUSTAKA}

Dewi, T. U., Hidayatullah, S., \& Puspitasari, N. A. (2020). Analisis Nilai Karakter dalam

Naskah Wawacan Samun. Manuskripta, 10(2), 283.

Hidayatullah, S. (2020). Religiositas Masyarakat Betawi Dalam Folklor. Aksara, 32(1), 79- 
94. https://doi.org/10.29255/aksara.v32i1.478.79-94

Mangunwijaya, Y. B. (1994). Sastra dan Religiositas. Yogyakarta: Kanisius.

Moleong, L. J. (2013). Metodologi Penelitian Kualitatif (Cetakan Ke). Bandung: PT. Remaja Rosdakarya.

Muplihun, E. (2016). Nilai Moral dalam Dwilogi Novel Saman dan Larung Karya Ayu Utami. Jurnal Pendidikan Bahasa Dan Sastra Indonesia (JP-BSI), 01.

Nurgiyantoro, B. (2015). Teori pengkajian fiksi / Burhan Nurgiyantoro. In Teori Pengkajian Fiksi. https://doi.org/10.1177/0192623316675767

Purwaningsih, E. (2010). Keluarga dalam Mewujudkan Pendidikan Nilai sebagai Upaya Mengatasi Degradasi Nilai Moral. Jurnal Pendidikan Sosiologi Dan Humaniora, 01.

Puspitasari, N. A., Hidayatullah, S., \& Jupri, A. R. (2018). Pembentukkan Karakter Anak dengan Menulis Dongeng. In Pesona: Pekan Seminar Nasional Pendidikan Bahasa dan Sastra Indonesia (Vol. 1, pp. 61-66).

Ratna, N. K. (2013). Teori, Metode, dan Teknik Penelitian Sastra. Yogyakarta: Pustaka Pelajar.

Safitri, R. A. (2020). Kritik Sosial Dalam Naskah Drama Bunga Rumah Makan Karya Utuy Tatang Sontani. Imajeri: Jurnal Pendidikan Bahasa Dan Sastra Indonesia, 3(1), 67-73.

Solihati, N., Hikmat, A., Jupri, A. R., \& Hidayatullah, S. (2019). Character Education Value in Folk Games on Merapi Mountain Slope. Jurnal Kependidikan: Penelitian Inovasi Pembelajaran, 3(1).

Wiyatmi. (2006). Pengantar Kajian Sastra. Yogyakarta: Pustaka.

Youpika, F., \& Zuchdi, D. (2016). Nilai pendidikan karakter cerita rakyat Suku Pasemah Bengkulu dan relevansinya sebagai materi pembelajaran sastra. Jurnal Pendidikan Karakter, (1).

Zubaidi. (2012). Desain Pendidikan Karakter. Jakarta: Kencan Media Prenada Group. Zuriah, N. (2015). Pendidikan Moral dan Budi Pekerti dalam Perspektif Perubahan. Jakarta: Bumi Aksara. 